
мониторинга хронических неинфекционных заболеваний

П.В. Селиверстов ${ }^{1 \bowtie}$, ORCID: 0000-0001-5623-4226, e-mail: seliverstov-pv@yandex.ru

С.P. Бакаева ${ }^{1}$, ORCID: 0000-0002-4297-8918, e-mail: sshaidullina@yandex.ru

B.B. Шаповалов², ORCID: 0000-0002-9764-4018, e-mail: valshapovalov@mail.ru

${ }^{1}$ Северо-Западный государственный медицинский университет им. И.И. Мечникова; 191015, Россия, Санкт-Петербург, ул. Кирочная, д. 41

2 Санкт-Петербургский государственный электротехнический университет «ЛЭТИ»; 197376, Россия, Санкт-Петербург, ул. Профессора Попова, д. 5

\title{
Резюме
}

На сегодняшний день во многих странах мира отмечается неуклонный рост государственных расходов, связанных со здравоохранением. Одним из перспективных вариантов оптимизации этих затрат является повсеместное распространение телемедицины как способа дистанционного медицинского обслуживания. Известно, что основной вклад в здоровье отдельного человека и населения в целом вносит образ жизни. Эффективный скрининг, своевременное выявление факторов риска и заболеваний на ранних этапах их развития, диспансеризация, повсеместное открытие центров здоровья, кабинетов профилактики, школы здоровья - все эти мероприятия направлены на увеличение продолжительности и повышение качества жизни нации. Несмотря на доступность и относительно низкую стоимость известных программ для дистанционного скрининга, нельзя не упомянуть и их существенные минусы: отсутствие итоговых аналитических документов, охват одной или нескольких систем, необходимость очного визита к врачу для расчета рисков и определения дальнейшей тактики ведения пациента. В статье предлагается методология телемедицинского скрининга здоровья взрослого населения в амбулаторном звене с использованием системы анализа неструктурированных данных при популяционном мониторинге хронических неинфекционных заболеваний. Разработка основана на расчете рисков с помощью метода «Решающих правил», в качестве средства описания использована теория нечетких множеств. Результатом разработанной авторами методики является вариант телемедицинского анкетного скрининга, позволяющий определять риски здоровью по конкретным профилям, формировать итоговое заключение с рекомендациями по здоровому образу жизни, дальнейшему обследованию, лечению и профилактике хронических заболеваний. Разработка может использоваться в государственных и частных лечебно-профилактических учреждениях. Особый интерес представляет возможность интеграции программного обеспечения в медицинскую практику в сегодняшних условиях пандемии, а также в государственные проекты «Бережливая поликлиника», «Арктический доктор» и «Земский доктор».

Ключевые слова: телемедицина, профилактика, скрининг, расчет рисков, хронические неинфекционные заболевания

Благодарности. Проект разработки телемедицинской платформы стал победителем конкурса «УМНИК» в рамках национальной программы «Цифровая экономика Российской Федерации». Данное исследование проводится при поддержке Фонда содействия инновациям по договору №66ГУЦЭС8-D3/56432 от 21.12.2019 г. Также в рамках выполнения работ по договору на разрабатываемую программу получено свидетельство о государственной регистрации программы для ЭВМ №2020611264.

Для цитирования: Селиверстов П.В., Бакаева С.Р., Шаповалов В.В. Разработка медицинской методологии телемедицинского скрининга здоровья взрослого населения в амбулаторном звене для популяционного мониторинга хронических неинфекционных заболеваний. Медицинский совет. 2020;(11):202-209. doi: 10.21518/2079-701X-2020-11-202-209.

Конфликт интересов: авторы заявляют об отсутствии конфликта интересов.

\section{Development of a medical methodology for telemedicine screening of adult health in outpatient settings for population monitoring of chronic noncommunicable diseases}

Pavel V. Seliverstov ${ }^{1 凶}$, ORCID: 0000-0001-5623-4226, e-mail: seliverstov-pv@yandex.ru

Sofia R. Bakaeva1 ${ }^{1}$, ORCID: 0000-0002-4297-8918, e-mail: sshaidullina@yandex.ru

Valentin V. Shapovalov², ORCID: 0000-0002-9764-4018, e-mail:valshapovalov@mail.ru

${ }^{1}$ North-Western State Medical University named after I.I. Mechnikov; 41, Kirochnaya St., St Petersburg, 191015, Russia

2 Saint Petersburg Electrotechnical University “LETI”; 5, Prof. Popov, St Petersburg, 197376, Russia

\section{Abstract}

Today, in many countries of the world, there is a steady increase in public spending related to health. One of the promising options for optimizing these costs is the widespread use of telemedicine as a method of remote medical care. It is known that the main 
contribution to the health of an individual and the population as a whole is made by lifestyle. Effective screening, timely detection of risk factors and diseases at the early stages of their development, medical examinations, universal opening of health centers, prevention offices, health schools - all these measures are aimed at increasing the duration and quality of life of the nation. Despite the availability and relatively low cost of well-known programs for remote screening, it is impossible not to mention their significant disadvantages: the lack of final analytical documents, the coverage of one or more systems, the need for a face-to-face visit to the doctor to calculate risks and determine further patient management tactics. The article proposes a methodology for telemedicine screening of adult health in outpatient settings using a system for analyzing unstructured data for population monitoring of chronic non-communicable diseases. The development is based on risk calculation using the method of "decision rules" as a means of description used in the theory of fuzzy sets. The result of the method developed by the authors is a variant of telemedicine questionnaire screening, which allows determining health risks by specific profiles, forming a final conclusion with recommendations for a healthy lifestyle, further examination, treatment and prevention of chronic diseases. The development can be used in public and private medical institutions. Of particular interest is the possibility of integrating software into medical practice in the current conditions of the pandemic, as well as in the state projects "Lean polyclinic", "Arctic doctor" and "Zemsky doctor".

Keywords: telemedicine, prevention, screening, risk assessment, chronic non-communicable diseases

Acknowledgments. The telemedicine platform project won the UMNIK (Brainbox) competition within the framework of the Digital Economy national program of the Russian Federation. This study is conducted with support of the Innovation Promotion Fund under contract No. 66GUTCES8-D3/56432 dated December 21, 2019. Also, a certificate of state registration of software application No. 2020611264 was obtained as part of the work under the software application contract.

For citation: Seliverstov P.V., Bakaeva S.R., Shapovalov V.V. Development of a medical methodology for telemedicine screening of adult health in outpatient settings for population monitoring of chronic noncommunicable diseases. Meditsinskiy sovet = Medical Council. 2020;(11):202-209. (In Russ.) doi: 10.21518/2079-701X-2020-11-202-209.

Conflict of interest: The authors declare no conflict of interest.

Главное предназначение врача состоит в научении людей быть здоровыми и в лечении тех, кого не удалось обучить этому.

Н.И. Пирогов

\section{ВВЕДЕНИЕ}

На протяжении ряда последних лет система здравоохранения главным образом была ориентирована на лечение больных людей. Однако правительство РФ поставило новую задачу - охрана здоровья человека. В связи с этим государственная политика сегодняшнего дня сосредоточена на увеличении продолжительности жизни и на своевременной профилактике заболеваний для сохранения здоровья всех групп населения.

Еще великий русский хирург и ученый Н.И. Пирогов говорил о том, что фунт профилактики стоит пуда лечения. А что же сегодня? На сегодняшний день здоровый образ жизни (ЗОЖ) рассматривается как основной параметр, определяющий состояние здоровья не только нации в целом, но и каждого человека в отдельности. Поэтому государство приняло решение о создании центров здоровья, кабинетов профилактики и программ, позволяющих проводить скрининг для выявления факторов риска и заболеваний на ранних этапах их развития. Подобная практика с использованием скрининговых программ в настоящее время широко распространена во всем мире, поскольку имеет научное подтверждение своей эффектИВнОсти ${ }^{1}$.

В своем ежегодном Послании Федеральному собранию в 2019 г. Владимир Путин говорил о необходимости развития телемедицины в России: «На повышение доступ1 Официальные сетевые ресурсы президента России: официальный сайт. Режим доступа:
http://kremlin.ru (дата обращения 09.04.2020). Режим доступа: https://apps.who.int/iris/bitstream/handle/10665/44497/9789244564141_rus.pdf (дата обращения 09.04.2020). ности медицинской помощи должна работать информатизация здравоохранения. В течение трех лет надо отладить электронное взаимодействие между медицинскими учреждениями, аптеками, врачами и пациентами»².

\section{ТЕЛЕМЕДИЦИНА СЕГОДНЯ}

Для термина «телемедицина» существует множество определений. Согласно ВОЗ, телемедицина - это предоставление услуг здравоохранения, в условиях, когда расстояние является критическим фактором, работниками здравоохранения, использующими информационнокоммуникационные технологии (ИКТ) для обмена необходимой информацией в целях диагностики, лечения и профилактики заболеваний и травм, проведения исследований и оценок, а также для непрерывного образования медицинских работников в интересах улучшения здоровья населения и развития местных

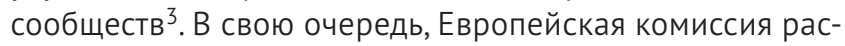
сматривает термин более конкретно и предлагает следующую его трактовку: «Телемедицина - это оперативный удаленный доступ к услугам медицинских специалистов с помощью ИКТ вне зависимости от того, где находится пациент или где хранится соответствующая информация» [EHTEL, 2008]. Американская ассоциация телемедицины (American Telemedicine Association, ATA) предлагает свое определение, согласно которому телемедицина - это использование медицинской информации, предоставленной одной стороной другой стороне с помощью электронных средств коммуникации, для улуч-

2 О Стратегии развития здравоохранения в Российской Федерации на период до 2025 г. Указ Президента РФ от 6 июня 2019 г. №254. Режим доступа: https://www.garant.ru/products/ipo/ prime/doc/72164534/ (дата обращения 09.04.2020).

3 Всемирная организация здравоохранения. Доклад о результатах второго глобального обследования в области электронного здравоохранения. 2012 г. Режим доступа: https://apps.who.int/ iris/bitstream/handle/10665/44497/9789244564141_rus.pdf. 
шения состояния здоровья пациентов ${ }^{4}$. Несмотря на то что каждая организация предлагает свою трактовку термина, в каждом из вышеописанных определений выделяются три основные характеристики телемедицины: повышение качества здравоохранения, использование ИКТ и удаленный доступ [1].

Также среди основных преимуществ телемедицины особое значение занимают ${ }^{5}$ : снижение количества врачебных ошибок; экономия времени врача и пациента; повышение эффективности работы медицинских учреждений; качественная диагностика и своевременная профилактика заболеваний среди населения, проживающего в труднодоступных и отдаленных от районных центров территориях [2].

В том или ином виде телемедицина существовала еще много веков назад, когда древние цивилизации сигнализировали друг другу с помощью огня и дыма о надвигающейся опасности, например о вспышке инфекции [3]. В 1905 г. Эйтховен впервые передал ЭКГ по телефону. С 1922 г. в университетском госпитале Готтенбурга по радиоканалам проводились медицинские консультации моряков, находящихся в плавании. В 1959 г. в США была проведена первая телевизионная консультация психиатрического больного. В 1965 г. американский кардиохирург М. Дебеки через канал спутника связи консультировал хирургов, проводящих операцию в Женеве. В 1999 г. Дж. Нильсен, работавшая в качестве врача на научно-исследовательской станции Амундсен - Скотт в Антарктиде, обнаружила уплотнение в молочной железе. Из-за трудных погодных условий вся диагностика и лечение проводились с помощью спутниковой связи, электронной почты и видеоконференций. Благодаря связи со специалистами Дж. Нильсен самостоятельно выполнила биопсию и диагностировала рак молочной железы. Лечение проводилось химиопрепаратами, сброшенными пилотами ВВС США 6 .

На сегодняшний день во многих развитых и развивающихся странах мира отмечается неуклонный рост государственных расходов, связанных со здравоохранением. Одним из возможных вариантов оптимизации подобных затрат рассматривается распространение телемедицины как способа дистанционного медицинского обслуживания на основе информационных и коммуникационных технологий (ИКТ) [4].

Согласно приказу М3 РФ №344, РАМН №76 от 27.08.2001 «Об утверждении Концепции развития телемедицинских технологий в Российской Федерации и

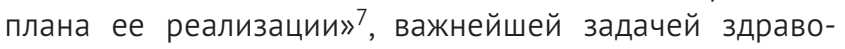
охранения цивилизованного государства, способствующей

\footnotetext{
${ }^{4}$ Американская ассоциация телемедицины: официальный сайт. Available at: https://www. americantelemed.org (дата обращения 01.03.2020).

5 О внесении изменений в отдельные законодательные акты Российской Федерации по вопросам применения информационных технологий в сфере охраны здоровья. Федеральный закон РФ от 29.07.2017 №242-Ф3. Режим доступа: http://www.consultant.ru/document/ cons_doc_LAW_221184/ (дата обращения 09.04.2020).

${ }^{6}$ Alsup D. Doctor rescued from Antarctica in 1999 dies at 57. CNN2009. Available at: http:// www.cnn.com/2009/HEALTH/06/23/obit.jerri.nielsen/index.html.

Об утверждении Концепции развития телемедицинских технологий в Российской Федерации и плана ее реализации. Приказ Минздрава РФ №344, РАМН №76 от 27.08.2001. Режим доступа: http://www.consultant.ru/document/cons_doc_LAW_98525 (дата обращения 09.04.2020).
}

стабильности общества, является обеспечение права гражданина на медицинское обслуживание независимо от его социального положения и места жительства. Таким образом, развитие телемедицины позволит решить важнейшую проблему российского здравоохранения: обеспечение медицинской помощью населения на всей территории нашей страны с учетом существующего неравномерного распределения населения и сосредоточенности ведущих специалистов в крупных городах.

В 2010 г. ВО3 определила четыре характерных принципа телемедицины [WHO 2010]: предоставление клинической поддержки, преодоление географических барьеров и установление связи между пользователями, физически находившимися на удалении друг от друга, использование различных видов ИКТ, улучшение здоровья населения ${ }^{8}$.

Кроме того, по срокам передачи информации и взаимодействия между участвующими в процессе лицами В03 разделяет телемедицину на 2 типа: синхронную и асинхронную9. Асинхронная телемедицина использует обмен предварительно записанными данными между двумя или более лицами в разное время. Примером асинхронной телемедицины может служить отправка врачу-эксперту посредством электронной почты клинического случая, после чего врач отправляет обратно свое мнение по поводу диагноза, оптимальной терапии и 30ж. Синхронная телемедицина подразумевает режим реального времени и требует одномоментного присутствия участников процесса, например при проведении видеоконференций, общении по телефону или с использованием сети Интернет. И в синхронной, и в асинхронной телемедицине информация может передаваться в различных формах: в виде текста, аудио, видео или изображения [5].

Отдельно можно выделить удаленный мониторинг форму телемедицины, предполагающую удаленное наблюдение медицинскими работниками за состоянием пациента с помощью различных технических устройств. Полученные в ходе мониторинга данные собираются дистанционно и передаются в медицинское учреждение для последующего анализа и интерпретации [2, 6]. Удаленный мониторинг используется для динамического наблюдения за пациентами с заболеваниями сердечнососудистой системы, сахарным диабетом, бронхиальной астмой, а также для наблюдения за пациентами в домашних условиях ${ }^{10}$.

С помощью телемедицины возможно достижение следующих целей ${ }^{11}$ :

- доступность качественной медицинской помощи для всего населения Российской Федерации независимо от места жительства и социального положения конкретного гражданина;

${ }_{8}^{8}$ Всемирная организация здравоохранения. Доклад о результатах второго глобального обследования в области электронного здравоохранения. 2012 г. Available at: https://apps.who. int/iris/bitstream/handle/10665/44497/9789244564141_rus.pdf.

${ }^{9}$ Там же.

${ }^{10}$ Американская ассоциация телемедицины: официальный сайт. Available at: https://www. americantelemed.org (дата обращения 01.03.2020).

${ }^{11}$ Центральный научно-исследовательский институт организации и информатизации здравоохранения МЗ РФ: официальный сайт. Режим доступа: https://old.mednet.ru/images/ stories/files/telemed/Deklaraciya.pdf (дата обращения 09.04.2020). 
полноценная интеграция превентивной медицины в систему оказания медицинской помощи;

- создание рабочих мест для медицинского и технического персонала;

- оптимизация затрат на здравоохранение за счет снижения числа врачебных ошибок и своевременной профилактики хронических неинфекционных заболеваний;

дистанционный процесс переподготовки медицинских кадров;

- персонифицированный подход.

Что касается правовой стороны вопроса, то предпосылки к развитию в стране телемедицины появились еще в 2001 г. с упомянутого выше приказа М3 РФ №344, РАМН №76 от 27.08.2001 «Об утверждении Концепции развития телемедицинских технологий в Российской Федерации и плана ее реализации». Согласно документу, стратегически важной задачей в условиях реформирования здравоохранения являлась организация взаимодействия лечебно-профилактических учреждений (ЛПУ) со специализированными учреждениями здравоохранения путем дистанционного оказания высококвалифицированной помощи населению, используя современные информационно-телекоммуникационные технологии и интеллектуальный потенциал лучших клиник в условиях сокращения коечного фонда при одновременном ускорении лечебно-диагностического процесса ${ }^{12}$.

Позднее, в 2017 г., вступил в силу Федеральный закон №242 от 29.07.2017 «О внесении изменений в отдельные законодательные акты Российской Федерации по вопросам применения информационных технологий в сфере охраны здоровья» ${ }^{13}$. Новый закон предусматривает значительное расширение возможности использования информационных технологий в системе здравоохранения. Кроме того, так называемый закон о телемедицине формирует правовое поле для дистанционного оказания медицинской помощи и выписки электронных рецептов.

Согласно статье 36.2 Федерального закона РФ №323 «Об основах охраны здоровья граждан» от 21.11.2011'14.

1. Медицинская помощь с применением телемедицинских технологий организуется и оказывается в порядке, установленном уполномоченным федеральным органом исполнительной власти, а также в соответствии с порядками оказания медицинской помощи и с учетом стандартов медицинской помощи (в редакции Федерального закона РФ от 25.12.2018 №489-Ф3).

2. Консультации пациента или его законного представителя медицинским работником с применением телемедицинских технологий осуществляются в целях:

профилактики, сбора, анализа жалоб пациента и данных анамнеза, оценки эффективности лечебно-диагно-

\footnotetext{
12 Об утверждении Концепции развития телемедицинских технологий в Российской Федерации и плана ее реализации. Приказ Минздрава РФ №344, РАМН №76 от 27.08.2001. Режим доступа: http://www.consultant.ru/document/cons_doc_LAW_98525 (дата обращения 09.04.2020).

13 О внесении изменений в отдельные законодательные акты Российской Федерации по вопросам применения информационных технологий в сфере охраны здоровья. Федеральный закон РФ от 29.07.2017 №242-Ф3. Режим доступа: http://www.consultant.ru/document/ cons doc LAW 221184 (дата обращения 09.04.2020)

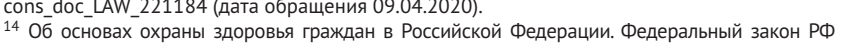
от 21.11.2011№323-Ф3. Режим доступа: http://www.consultant.ru/document/cons_doc_ LAW_121895 (дата обращения 09.04.2020).
}

стических мероприятий, медицинского наблюдения за состоянием здоровья пациента;

- принятия решения о необходимости проведения очного приема (осмотра, консультации).

3. При проведении консультаций с применением телемедицинских технологий лечащим врачом может осуществляться коррекция ранее назначенного лечения при условии установления им диагноза и назначения лечения на очном приеме (осмотре, консультации).

4. Дистанционное наблюдение за состоянием здоровья пациента назначается лечащим врачом после очного приема (осмотра, консультации). Дистанционное наблюдение осуществляется на основании данных о пациенте, зарегистрированных с применением медицинских изделий, предназначенных для мониторинга состояния организма человека, и (или) на основании данных, внесенных в единую государственную информационную систему в сфере здравоохранения, или государственную информационную систему в сфере здравоохранения субъекта Российской Федерации, или медицинскую информационную систему, или информационные системы, указанные в ч. 5 ст. 91 настоящего Федерального закона.

5. Применение телемедицинских технологий при оказании медицинской помощи осуществляется с соблюдением требований, установленных законодательством Российской Федерации в области персональных данных, и врачебной тайны.

6. В целях идентификации и аутентификации участников дистанционного взаимодействия при оказании медицинской помощи с применением телемедицинских технологий используется единая система идентификации и аутентификации.

7. Документирование информации об оказании медицинской помощи пациенту с применением телемедицинских технологий, включая внесение сведений в его медицинскую документацию, осуществляется с использованием усиленной квалифицированной электронной подписи медицинского работника.

В октябре 2017 г. Росстандартом утвержден ГОСТ Р 57757-2017 «Дистанционная оценка параметров функций, жизненно важных для человека». Таким образом, согласно новому стандарту, были унифицированы требования к технологиям и процессам дистанционного скрининга, их передаче и оценке медицинским персоналом. Также в ГОСТе содержатся требования к пользователям, необходимому оборудованию, программному обеспечению и технологиям в системе дистанционного взаимодействия ${ }^{15}$.

В 2018 г. 37\% граждан страны обращались за медицинской помощью посредством дистанционных программ. При этом наименьший интерес к телемедицине продемонстрировали жители Санкт-Петербурга и Ленинградской области - 9 и 1\% соответственно. Такая

15 ГОСТ Р 57757-2017 Дистанционная оценка параметров функций жизненно важных для жизнедеятельности человека. Общие требования (2018). М.: Стандартинформ; 2017. Режим доступа: http://docs.cntd.ru/document/1200157018. 
тенденция может быть связана с высоким уровнем жизни, доступностью качественной медицинской помощи, в том числе развитой системы коммерческого здравоохранения, а также высоким процентом людей старшего возраста, которые выбирают традиционные методы медицинской помощи. Согласно описанным данным, в 41\% случаев после дистанционного обращения за медицинской помощью последующая очная консультация не потребовалась, 20\% обратившихся повторно записывались к тому же специалисту, а в 30\% случаев пациенты сразу направлялись к узкопрофильному специалисту без повторной консультации терапевта ${ }^{16}$.

Таким образом, внедрение телемедицины позволит снизить издержки здравоохранения [7, 8]. Сокращение расходов здравоохранения будет достигнуто за счет снижения расходов на госпитализацию, транспортировку пациентов, косвенных затрат, связанных с отъездом из дома или места работы [9]. Согласно опубликованным результатам наблюдения за группой пациентов в Нижегородской области, телемедицинские технологии позволили сократить издержки в изучаемой группе на 5,9\%. Экономия обеспечивалась за счет сокращения числа дней лечения в стационаре ${ }^{17}$.

В общей сложности по результатам нескольких отечественных и иностранных исследований продемонстрировано снижение затрат при использовании телемедицины в сравнении с традиционными методами, при этом экономия составила от 2 до $73 \%{ }^{18}$ [7]. В РФ оказывать телемедицинские услуги могут специалисты, включенные в Федеральный регистр медицинских работников, при этом организация, в которой консультируют врачи, должна быть занесена в Федеральный реестр. Врачи могут получать данные о пациенте из Единой базы медицинских данных (ЕМИАС) и Единой государственной информационной системы в сфере здравоохранения (ЕГИСЗ). Используя вышеперечисленные базы данных, специалисты из столичных медицинских центров могут взаимодействовать с региональными врачами, консультировать и давать квалифицированные заключения.

Таким образом, телемедицинские консультации «врач - врач» позволят повысить качество оказываемых услуг путем привлечения более опытных или узкопрофильных специалистов. Электронное взаимодействие между врачом и пациентом (врач - пациент) даст возможность проводить первичные медицинские консультации для установления диагноза, назначения плана обследования и лечения, получать мнение другого специалиста для оценки ранее полученного заключения, а также дистанционно контролировать результаты терапии после очной консультации.

\footnotetext{
16 Дмитриева А. Эксперты: телемедицина требует развития инфраструктуры в сельской местности и внедрения мобильного приложения для взаимодействия между врачами и пациентами. 2019. Режим доступа: http://www.garant.ru/article/1261440/.

17 Леванов В.М. Научное обоснование использования электронных технологий в условиях модернизации здравоохранения на региональном уровне: дис. ... д-ра мед. наук: 14.02.03. М.; 2013. Режим доступа: http://medical-diss.com/medicina/nauchnoe-obosnovanieispolzovaniya-elektronnyh-tehnologiy-v-usloviyah-modernizatsii-zdravoohraneniya-naregionalnom-urovn.

18 Там же.
}

На сегодняшний день наибольшие сложности возникают при взаимодействии «врач - пациент». Во-первых, это невозможность контроля за достоверностью предоставленных пациентом данных, во-вторых, необходимость получения врачом электронной подписи, а для пациента - аутентификации на портале государственных услуг. Однако, несмотря на существующие трудности, электронное взаимодействие между врачами и пациентами имеет свои несомненные плюсы: возможность получать высококвалифицированную помощь на всей территории страны, привлекать других специалистов для анализа правильности рекомендованного плана обследования и лечения, а также отправлять данные о состоянии своего здоровья в медицинские организации посредством личного кабинета и медицинских приложений [10].

Сегодня можно смело говорить о том, что тенденции развития профилактических обследований, по крайней мере первого этапа, основной задачей которого является формирование групп риска по различным ХНИЗ, должны быть направлены на разработку дистанционных методов контроля состояния человека. Так, сложившаяся в мире ситуация с пандемией COVID-19 резко усиливает эти тенденции и заставляет по-новому взглянуть и переосмыслить организацию работы с пациентом [11].

В перспективе для более качественного оказания дистанционной медицинской помощи населению необходимо развитие инфраструктуры, запуск медицинских приложений, отслеживающих основные показатели состояния пациента, анализируя которые лечащий врач сможет корректировать терапию, и привлечение к процессу страховых компаний ${ }^{19}[12,13]$.

Таким образом, в России созданы все предпосылки для появления собственных разработок с использованием телемедицинских технологий [14]. Однако среди известных программ, наряду с их несомненными плюсами, такими как доступность для населения, возможность дистанционного обследования, относительно низкая стоимость скрининга, есть и минусы: отсутствие итоговых аналитических документов, охват одной или нескольких систем, необходимость очного визита к врачу для расчета рисков и определения дальнейшей тактики ведения пациента.

Опираясь на опыт отечественных и иностранных коллег, мы разработали собственный вариант телемедицинского анкетного скрининга здоровья взрослого населения. Новизна нашей разработки заключается в создании оригинальных тестов/вопросов, алгоритмов сравнения и анализа результатов, модели оценки возникновения рисков по симптомам с использованием теоретических знаний, практического опыта и современных рекомендаций.

За последние полтора года авторами проведена большая работа по созданию телемедицинской системы анкетного скрининга, методологии отбора и ранжирова19 Дмитриева А. Эксперты: телемедицина требует развития инфраструктуры в сельской
местности и внедрения мобильного приложения для взаимодействия между врачами и пациентами. 2019. Режим доступа: http://www.garant.ru/article/1261440/. 
ния вопросов, обладающих наибольшей информативностью, простотой и доступностью констатации с учетом комплексного подхода.

Исследование проведено на кафедре внутренних болезней, клинической фармакологии и нефрологии СЗГМУ им. И.И. Мечникова на основе разработанного нами медицинского обеспечения телемедицинской платформы. В исследовании приняли участие 139 человек: 97 женщин и 42 мужчины, средний возраст обследуемых составил $65 \pm 13,8$ лет.

В качестве оценки рисков здоровья в телемедицинской системе нами была использована не нозологическая единица, а профиль патологии, в котором набор аналитических признаков, данные объективного обследования и жалобы были сортированы по группам. Для проведения многопрофильного комплексного анкетного скрининга здоровья были сформулированы 198 вопросов, которые были структурированы по 5 профилям патологии: кардиология, эндокринология, гастроэнтерология, пульмонология и онкология. Выбор данных профилей патологии неслучаен - со второй половины XX в. основными причинами смерти стали хронические неинфекционные заболевания (ХНИЗ): болезни системы кровообращения (БСК), хронические бронхолегочные, онкологические заболевания и сахарный диабет. В Российской Федерации ежегодно около 75\% всех смертей приходится на хронические неинфекционные заболевания, при этом особенно высокая смертность наблюдается среди лиц трудоспособного возраста [15, с. 5-6]. Кроме того, за последние годы увеличилась распространенность болезней органов пищеварения [16].

Bсе объективно констатируемые признаки каждого профиля оценивались по степени их выраженности или достоверности наличия. Минимальные отклонения принимались за раннее выявление патологии или низкий риск в тех случаях, когда оно сочетается с какими-либо жалобами или особенностями развития, отмеченными в анкете. Кроме выделения степени выраженности, программа предусматривает отнесение симптома или признака к патологии нескольких систем, так как они могут проявляться зачастую при поражении разных органов, в связи с чем расчет спектра рисков заболевания проводится системой по всем пяти профилям. В свою очередь, система настроена на границу между группой риска и патологией, оцененной в 50 баллов, а диапазон группы риска сосредоточен в промежутке от 20 до 50 баллов. Расчет рисков проводится методом решающих правил, а в качестве средства описания используется теория нечетких множеств. Характерными особенностями используемого математического аппарата являются, с одной стороны, возможность формализовать представления о степени выраженности того или иного признака, а с другой стороны, адекватность медицинской логике.

При помощи разработанной технологии было установлено, что у 33,8\% обследуемых диагностирован низкий риск сердечно-сосудистых заболеваний, у 41,7\% средний риск, у $24,5 \%$ - высокий риск. При анализе ответов на вопросы гастроэнтерологического профиля у $33,1 \%$ определялся низкий риск заболеваний ЖКТ, у $46,8 \%$ - средний риск и у 20,1\% - высокий риск. У 46,7\% обследуемых зафиксирован низкий риск по профилю «Пульмонология», у 40,3\% - средний и у $13 \%$ - высокий риск. У 6,5\% проанкетированных диагностирован низкий риск по профилю «Эндокринология», у 23,7\% - средний риск, у 69,8\% - высокий риск, однако данный профиль требует доработки в связи с неспецифичностью эндокринологических жалоб. Низкий риск развития онкологических заболеваний имеют 18\% обследуемых, 32,4\% - средний риск, у 49,6\%, согласно данным анкет, диагностирован высокий риск опухолевых заболеваний, что требует повышенной онкологической настороженности в данной группе обследуемых. Средний балл обследуемых по кардиологическому профилю составил 517, по гастроэнтерологическому - 440, 439 баллов - среднее значение по профилю «Пульмонология», 495 баллов - по профилю «Эндокринология» и 533 балла - среднее значение в профиле «Онкология». У 12 обследуемых (8,6\%) выявлен высокий риск по всем 5 профилям патологии. И лишь у 7 (5\%) обследуемых диагностирован низкий риск по всем профилям патологии.

Программа проанализировала полученные данные и предложила соответствующие рекомендации. Так, при низком риске развития заболеваний по всем 5 профилям патологии рекомендовано соблюдение правил здорового образа жизни, включающих в себя принципы правильного питания, контроль массы тела, адекватную физическую нагрузку, отказ от вредных привычек и прохождение диспансеризации согласно установленным срокам. Для среднего риска развития заболеваний, в зависимости от профиля патологии, кроме приверженности к здоровому образу жизни, рекомендован ежедневный контроль артериального давления, а также определен набор необходимых лабораторных и инструментальных обследований, вакцинопрофилактика. Для высокого риска патологий к уже упомянутым назначениям программа рекомендует очную консультацию врача для определения дальнейшей тактики обследования и лечения такого пациента, а также диспансерное наблюдение у соответствующего специалиста по месту жительства.

\section{ЗАКЛЮЧЕНИЕ}

Таким образом, разработанная нами программа позволяет определять степень существующего риска здоровью по конкретным профилям (кардиология, гастроэнтерология, пульмонология, эндокринология, онкология), формировать итоговое заключение и рекомендации по здоровому образу жизни, дальнейшему обследованию, лечению и профилактике хронических заболеваний.

Инновационность разработки заключается в собственной методологии отбора и ранжирования клинических симптомов и признаков заболеваний с учетом степени их выраженности и достоверности. Выделенные симптомы и признаки заболеваний формируют не нозо- 
логическую единицу, а профиль патологии, в связи с чем обладают наибольшей информативностью, доступностью констатации и охватывают все основные системы организма. Кроме того, разработан оригинальный кейс итоговых документов с рекомендациями по модификации образа жизни.

Преимущества разработки заключаются в гибкости решающих правил, адекватном мнении врача-эксперта, удобстве и понятности представления итоговых результатов, формировании заключений по необходимому дообследованию и рекомендаций по приверженности к здоровому образу жизни, персонифицированном подходе, мобильности, отсутствии привязки к времени и месту, наличии обратной связи «врач - пациент». Кроме того, разработка позволяет сократить время приема пациента в амбулаторном звене на 20\% при использовании про- граммы в условиях учреждений первичной медико-санитарной помощи.

Конечными потребителями программного обеспечения могут быть государственные лечебно-профилактические учреждения, в том числе в рамках проекта «Бережливая поликлиника», «Арктический доктор», «Земский доктор», центры и кабинеты профилактики, а также частные лица и медицинские центры. Подобный широкий круг потребителей обусловлен современными реалиями цифрового здравоохранения и отвечает вызовам сложившейся ситуации с неинфекционной, инфекционной заболеваемостью, в том числе в условиях всеобщего карантина [17].

Поступила / Received: 06.05.2020 Поступила после рецензирования / Revised: 22.05.2020 Принята в печать / Accepted: 10.06 .2020

\section{Список литературь}

1. Kim J., Alanazi H., Daim T. Prospects for Telemedicine Adoption: Prognostic Modeling as Exemplified by Rural Areas of USA. Foresight and STI Governance. 2015;9(4):32-41. Available at: https://foresight-journal.hse.ru/ en/2015-9-4/168518790.html.

2. Nelson R. Telemedicine and Telehealth: The Potential to Improve Rural Access to Care. Am J Nurs. 2017;117(6):17-18. doi: 10.1097/01. NAJ.0000520244.60138.1c.

3. Hurst E.J. Evolutions in telemedicine: from smoke signals to mobile health solutions. J Hosp Librariansh. 2016:16(2):174-185. doi: 10.1080/15323269.2016.1150750.

4. Drake T.M., Ritchie J.E. The Surgeon Will Skype You Now: Advancements in E-clinic. Ann of Surgery. 2016;263(4):636-637. doi: 10.1097/ sla.0000000000001505.

5. Rao B., Lombardi A. $2^{\text {nd }}$. Telemedicine: current status in developed and developing countries. J Drugs Dermatol. 2009;8(4):371-375. Available at: https://www.ncbi.nlm.nih.gov/pubmed/19363855.

6. Weinstein R.S., Krupinski E.A., Doarn C.R. Clinical examination component of telemedicine, telehealth, mhealth, and connected health medical practices. Med Clin North Am. 2018;102(3):533-544. doi: 10.1016/j. mcna.2018.01.002.

7. Bongiovanni-Delarozière I., Le Goff-Pronost M. Economic evaluation methods applied to telemedicine: From a literature review to a standardized framework. European Research in Telemedicine. 2017;6(3-4):117-135. doi: 10.1016/j.eurtel.2017.08.002.

8. de la Torre-Díez I., López-Coronado M., Vaca C., Aguado J.S., de Castro C. Cost-utility and cost-effectiveness studies of telemedicine, electronic, and mobile health systems in the literature: a systematic review. Telemed J $E$ Health. 2015;21(2):81-85. doi: 10.1089/tmj.2014.0053.

9. Dowie R., Mistry H., Rigby M., Young T.A., Weather-burn G., Rowlinson G., Franklin R.C.G. A pediatric telecardiology service for district hospitals in south-east England: an observational study. Arch Dis Child. 2009:94(4):273 - 277. doi: 10.1136/adc.2008.138495.

10. Зайцева Н.А., Ширяева А.С. Телемедицина в современной системе здравоохранения. Бюллетень медицинских интернет-конференций. 2016;6(1):58. Режим доступа: https://medconfer.com/node/5613.

11. Smith W.R., Atala A.J., Terlecki R.P., Kelly E.E., Matthews C.A. Implementation Guide for Rapid Integration of an Outpatient Telemedicine Program during the COVID-19 Pandemic. J Am Coll Surg. 2020;231(2):216-222.e2. doi: 10.1016/j.jamcollsurg.2020.04.030.

12. Владзимирский А.В., Шадеркин И.А. Телемедицина в системе ОМС: перспектива или реальность. Здравоохранение. 2015;(11):64-73. Режим доступа: https://elibrary.ru/item.asp?id=24502358.

13. Болдырев Б.М. Телемедицина в страховании. Страховое дело. 2017;6(291):35-45. Режим доступа: http://ankil.info/lib/1/205/1819.

14. Баранов А.А., Вишнева Е.А., Намазова-Баранова Л.С. Телемедицина перспективы и трудности перед новым этапом развития. Педиатрическая фармакология. 2013;10(3):6-11. doi: 10.15690/pf.v10i3.691.

15. Арутюнов Г.П., Биличенко Т.Н., Бубнова М.Г., Ипатов П.В., Калинина А.М., Каприн А.Д. и др. Профилактика хронических неинфекционных заболеваний. Рекомендации. М.; 2013. 128 с. Режим доступа: http:// webmed.irkutsk.ru/doc/pdf/prevent.pdf.

16. Денисова Т.П., Шульдяков В.А., Тюльтяева Л.А., Черненков Ю.В., Алипова Л.Н., Саджая Л.А. Мониторинг распространенности заболеваний внутренних органов на примере патологии пищеварительной системы. Саратовский научно-медииинский журнал. 2011;7(4):772- 776. Режим доступа: http://ssmj.ru/system/files/201104_772-776.pdf.

17. Siddiqui J., Herchline T., Kahlon S., Moyer K.J., Scott J.D., Wood B.R., Young J. Infectious Diseases Society of America Position Statement on Telehealth and Telemedicine as Applied to the Practice of Infectious Diseases. Clinical Infectious Diseases. 2017;64(3):237-242. doi: 10.1093/cid/ciw773.

\section{References}

1. Kim J., Alanazi H., Daim T. Prospects for Telemedicine Adoption: Prognostic Modeling as Exemplified by Rural Areas of USA. Foresight and STI Governance. 2015;9(4):32-41. Available at: https://foresight-journal.hse.ru/ en/2015-9-4/168518790.html.

2. Nelson R. Telemedicine and Telehealth: The Potential to Improve Rural Access to Care. Am J Nurs. 2017;117(6):17-18. doi: 10.1097/01. NAJ.0000520244.60138.1c.

3. Hurst EJ. Evolutions in telemedicine: from smoke signals to mobile health solutions. J Hosp Librariansh. 2016;16(2):174-185. doi: 10.1080/15323269.2016.1150750.

4. Drake T.M., Ritchie J.E. The Surgeon Will Skype You Now: Advancements in E-clinic. Ann of Surgery. 2016;263(4):636-637. doi: 10.1097/ sla.0000000000001505.

5. Rao B., Lombardi A. $2^{\text {nd }}$. Telemedicine: current status in developed and developing countries. J Drugs Dermatol. 2009;8(4):371-375. Available at: https://www.ncbi.nlm.nih.gov/pubmed/19363855.

6. Weinstein R.S., Krupinski E.A., Doarn C.R. Clinical examination component of telemedicine, telehealth, mhealth, and connected health medical practices. Med Clin North Am. 2018;102(3):533-544. doi: 10.1016/j. mcna.2018.01.002.

7. Bongiovanni-Delarozière I., Le Goff-Pronost M. Economic evaluation methods applied to telemedicine: From a literature review to a standardized framework. European Research in Telemedicine. 2017;6(3-4):117-135. doi: 10.1016/j.eurtel.2017.08.002.

8. de la Torre-Díez I., López-Coronado M., Vaca C., Aquado J.S., de Castro C. Cost-utility and cost-effectiveness studies of telemedicine, electronic, and mobile health systems in the literature: a systematic review. Telemed J $E$ Health. 2015;21(2):81-85. doi: 10.1089/tmj.2014.0053.

9. Dowie R., Mistry H., Rigby M., Young T.A., Weather-burn G., Rowlinson G., Franklin R.C.G. A pediatric telecardiology service for district hospitals in south-east England: an observational study. Arch Dis Child. 2009;94(4):273-277. doi: 10.1136/adc.2008.138495.

10. Zaytseva N.A., Shiryaeva A.S. Telemedicine in the modern healthcare system. Byulleten' meditsinskikh internet-konferentsiy = Bulletin of Medical Internet Conferences. 2016;6(1):58. (In Russ.) Available at: https://medconfer.com/node/5613

11. Smith W.R., Atala A.J., Terlecki R.P., Kelly E.E., Matthews C.A. Implementation Guide for Rapid Integration of an Outpatient Telemedicine Program during the COVID-19 Pandemic. J Am Coll Surg. 2020;231(2):216-222.e2. doi: 10.1016/j.jamcollsurg.2020.04.030.

12. Vladzimirskiy A.V., Shaderkin I.A. Telemedicine in the compulsory health insurance system: perspective or reality. Zdravookhranenie $=$ Public Health Service. 2015;(11):64-73. (In Russ.) Available at: https://elibrary.ru/item. asp?id $=24502358$ 
13. Boldyrev B.M. Telemedicine in insurance. Strakhovoe delo $=$ Insurance Business 2017;6(291):35-45. (In Russ.) Available at: http://ankil.info/lib/1/205/1819/

14. Baranov A.A., Vishneva E.A., Namazova-Baranova L.S. Telemedicine - prospects and difficulties before a new development stage. Pediatricheskaya farmakologiya = Pediatric Pharmacology. 2013;10(3):6-11. (In Russ.) doi: 10.15690/pf.v10i3.691.

15. Arutyunov G.P., Bilichenko T.N., Bubnova M.G., Ipatov P.V., Kalinina A.M., Kaprin A.D. et al. Prevention of chronic non-communicable diseases. Recommendations. Moscow; 2013. 128 p. (In Russ.) Available at: http:// webmed.irkutsk.ru/doc/pdf/prevent.pdf
16. Denisova T.P., Shuldyakov V.A., Tyultyaeva L.A., Chernenkov Yu.V., Alipova L.N., Sadzhaya L.A. Monitoring of internal diseases dissemination (digestive disorders). Saratovskiy nauchno-meditsinskiy zhurnal = Saratov Journal of Medical Scientific Research. 2011;7(4):772-776. (In Russ.) Available at: http://ssmj.ru/system/files/201104_772-776.pdf.

17. Siddiqui J., Herchline T., Kahlon S., Moyer K.J., Scott J.D., Wood B.R Young J. Infectious Diseases Society of America Position Statement on Telehealth and Telemedicine as Applied to the Practice of Infectious Diseases. Clinical Infectious Diseases. 2017;64(3):237-242. doi: 10.1093/ cid/ciw773.

\section{Информация об авторах:}

Селиверстов Павел Васильевич, к.м.н., доцент кафедры внутренних болезней, клинической фармакологии и нефрологии, Федеральное государственное бюджетное образовательное учреждение высшего образования «Северо-Западный государственный медицинский университет имени И.И. Мечникова» Министерства здравоохранения Российской Федерации; 191015, Россия, Санкт-Петербург, ул. Кирочная, д. 41; e-mail: seliverstov-pv@yandex.ru

Бакаева Софья Рафаэлевна, клинический ординатор кафедры внутренних болезней, клинической фармакологии и нефрологии, Федеральное государственное бюджетное образовательное учреждение высшего образования «Северо-Западный государственный медицинский университет имени И.И. Мечникова» Министерства здравоохранения Российской Федерации; 191015, Россия, СанктПетербург, ул. Кирочная, д. 41; e-mail: sshaidullina@yandex.ru

Шаповалов Валентин Викторович, д.техн.н., профессор, профессор кафедры биотехнических систем, Федеральное государственное автономное образовательное учреждение высшего образования «Санкт-Петербургский государственный электротехнический университет «ЛЭТИ» Министерства науки и высшего образования Российской Федерации; 197376, Россия, Санкт-Петербург, ул. Профессора Попова, д. 5; е-таі: valshapovalov@mail.ru

\section{Information about the authors:}

Pavel V. Seliverstov, Cand. of Sci. (Med.), Associate Professor of the Department of Internal Diseases, Clinical Pharmacology and Nephrology, Federal State Budgetary Educational Institution of Higher Education "North-Western State Medical University named after I.I. Mechnikov" of the Ministry of Health of the Russian Federation; 41, Kirochnaya St., St Petersburg, 191015, Russia; e-mail: seliverstov-pv@yandex.ru

Sofia R. Bakaeva, resident physician of the Department of Internal Diseases, Clinical Pharmacology and Nephrology, Federal State Budgetary Educational Institution of Higher Education "North-Western State Medical University named after I.I. Mechnikov" of the Ministry of Health of the Russian Federation; 41, Kirochnaya St., St Petersburg, 191015, Russia; e-mail: sshaidullina@yandex.ru

Valentin V. Shapovalov, Dr. of Sci. (Tech.), Professor, Professor of the Department of biotechnical systems, Federal State Autonomous Educational Institution of Higher Education "St Petersburg Electrotechnical University “LETI” of the Ministry of Science and Higher Education of the Russian Federation; 5, Prof. Popov, St Petersburg, 197376, Russia; e-mail: valshapovalov@mail.ru 